\title{
Fatigue life prediction: A comparative study for a three layer EN45A parabolic leaf spring
}

\author{
Krishan Kumar* and M. L. Aggarwal
}

Assistant Professor, Mechanical Deptt., YMCA University of Science \& Technology, (A Haryana State Govt. University), Faridabad, Haryana, India

\begin{tabular}{l}
\hline A R T I C L E I N F O \\
\hline Article history: \\
Received 6 January, 2015 \\
Accepted 10 May 2015 \\
Available online \\
12 May 2015 \\
\hline Keywords: \\
Parabolic leaf spring \\
Fatigue life \\
CAE analysis
\end{tabular}

\section{A B S T R A C T}

\begin{abstract}
There are literally several studies accomplished to predict the fatigue life of leaf springs but estimation of fatigue life of a parabolic leaf spring by using CAE tools has not yet been executed in the past. Parabolic spring is an important component in a vehicle suspension system. It needs to have excellent fatigue life and in today's scenario manufacturers rely on constant loading fatigue analysis. The objective of this work is to perform the fatigue analysis of parabolic leaf spring by three different methods where CAE analysis is performed to observe the distribution of stress fatigue life and damage using Goodman approach. In this work, fatigue life of the parabolic leaf spring is determined as per SAE spring design manual and experimentally by testing on full scale fatigue testing machine. ANSYS is used for CAE solution for the prediction of leaf springs fatigue life considering stress theory. The fatigue life estimated by all three modes is then compared for the purpose of validation. The methodology used in this paper brings a practical approach to the professionals in the industries who are engaged for design of mechanical components.
\end{abstract}

\section{Introduction}

A spring is an elastic devise used to store mechanical energy, usually made out of hardened steel. Parabolic leaf spring is one of essential components in vehicle suspension system, which is commonly used in many heavy vehicles. It requires to have an excellent static load bearing capacity as well as fatigue life. Large vehicles require a good suspension system that can deliver a good ride and handling. The leaf spring is required to absorb the vertical vibrations due to road irregularities based on variations in the spring deflection to store the potential energy in spring as strain energy and to release slowly. Fatigue failure is one of the major issues in automotive components because at fluctuating stresses the vehicle structure may fail before achieving the failure stress of that material. That is why it is necessary to withstand numerous numbers of cycles before failure or never fail at all during the service period. This study is based on a numerical technique called the finite element method (FEM). Using FEA, the

\footnotetext{
* Corresponding author. Tel: +919896596710

E-mail addresses: er.krishanverma@yahoo.com (K. Kumar)
} 
parabolic leaf spring as shown in Fig. 1 is modeled using the discrete building blocks called elements. Each element has some equations that describe how it responds to certain loads. The sum of the response of all the elements in the model gives the total response of the design.

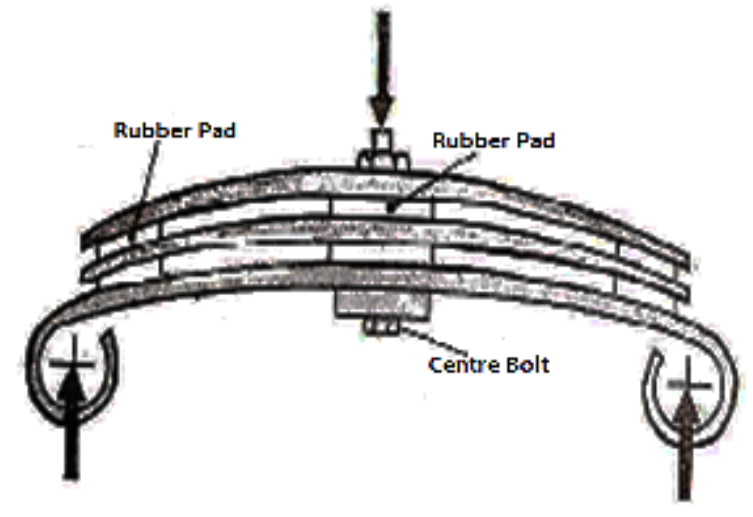

Fig.1: Parabolic Leaf Spring Assembly

Aggarwal and Chawla (2007) explained that fretting fatigue between leaves can be reduced by careful control of shot peening parameters. The bending strength of EN45A parabolic leaf spring is determined to be higher as compared with semi-elliptic leaf spring. Aggarwal et al. (2006 a) calculated axial fatigue strength of EN45A spring steel specimen experimentally as a function of shot peening in the conditions applied for full-scale leaf springs testing in industries. Optimum shot peening condition for specimen has been determined to correlate with $\mathrm{S} / \mathrm{N}$ curves of leaf springs. A mathematical model has been developed to forecast the fatigue life of leaf springs for a given stress at varying shot peening conditions. Predictions from this model are compared with experimental data. Aggarwal et al. (2006 b) identified the effect of shot flowrate on surface roughness. Full-scale laboratory testing of EN45A spring steel leaf springs was carried out to present improvement in fatigue life due to shot peening. Double shot peening was performed on leaf springs and its effects on surface roughness, compressive residual stress field, and fretting fatigue were noted. Aggarwal et al. (2005) evaluated axial fatigue strength of EN45A spring steel, experimentally. The effect of almen intensity on compressive residual stress has been discussed for fatigue life extension. Shot peening of leaf spring was illustrated to cause improvement in fatigue strength, reduction in weight and reliability. Aggarwal (2012) reported that residual stress field varies with shot peening intensity and affects weight of EN45A spring steel. A stress approach model for weight reduction of leaf spring has been experimentally developed simulating with industrial environment. Kanbolat et al. (2011) used a numerical approach to obtain the fatigue life and the leaf geometry against the environmental condition on the base of material properties. They presented a more precise method based on non-linear finite element solutions by evaluating the effects of the production parameters, the geometrical tolerances and the variations in the characteristics of the material. Scuracchio et al. (2013) described the role of shot peening in manufacturing leaf springs for vehicles, through the analysis of residual stresses by X-ray diffraction and fatigue tests on a series of samples that were subject to ten different peening schedules. Cerny and Mayer (2012) summarized the most important results of selected experimental programs on static and fatigue strength of heavy loaded components and joints made of glass reinforced plastic (GRP) composites, having been recently performed in fatigue laboratory of the SVUM research and testing institute. Refngah et al. (2009a) presented about fatigue life prediction based on finite element analysis and variable amplitude loading (VAL). Service loading of parabolic spring has been collected using data acquisition system. Finite element analysis (FEA) was performed on the spring model so stress and damage distribution can be observed. Experimental works was done in order to validate the FEA result. In Refngah et al. (2009b) finite element analysis was performed to analyze the stress distribution and behavior of both Multi-leaf and parabolic spring. Time histories service loading data was analyzed and damage area was simulated to predict the fatigue life of the components. Karthik et al. (2012) presented a fatigue life prediction based on finite element analysis under non constant amplitude proportional loading. The fatigue life simulation was performed using FEA and analyzed for different materials to observe the distribution 
of stress and damage. Kumar et al. (2013) performed CAE simulation for static and dynamic analysis of 65Si7 multi leaf spring and carried out a comparative study of CAE results with industrial experimental output for validation of CAE simulation. Deflection, stress and fatigue life were the parameters for this analysis. Kumar and Aggarwal (2013) carried out computer aided FEA simulation of a three-layer EN45A parabolic leaf spring. The finite element analysis (FEA) of the leaf spring has been carried out for deflection and stress and validated the work by performing the experiment with industrial interaction. Kumar and Vijayarangan (2007) described static and fatigue analysis of steel and composite multi leaf spring. The load carrying capacity, stiffness and weight of composite leaf spring are compared with that of steel leaf spring analytically and experimentally. Fatigue life of steel and composite leaf has also been predicted using life data analysis. Sustarsic et al. (2010) determined the fatigue life of $51 \mathrm{CrV} 4$ spring steel in different loading modes for two different heat treatment conditions using local stress gradient concept. Abdullah et al. (2008) simulated a parabolic leaf spring with variable amplitude loading (VAL) for the fatigue life assessment. The fatigue life \& damage using VAL was predicted and the result was correlated with FEA. The objective of this work is to perform the fatigue analysis of parabolic leaf spring by different methods. In this work fatigue life of the parabolic leaf spring is determined as per SAE spring design manual and experimentally by testing on full scale fatigue testing machine. ANSYS is used for CAE solution for the prediction of leaf springs fatigue life.

\section{Fatigue life of leaf spring}

Fatigue life is expressed by the number of deflection cycles, a leaf spring can withstand without failure. The main factors contributing to fatigue life includes number of load cycles experienced, range of stress and mean stress experienced in each load cycle. The best data are obtained by full-scale testing of actual components under realistic conditions which is usually expensive, time consuming and gives very specific results. In order to establish the fatigue life cycles which are acceptable in any spring design, it is desirable to have road durability tests run over a prescribed course so that fatigue life test data and actual road durability results may be correlated. It must be understood that the number of estimated life cycles is a statistical average and that fatigue test results will show scatter even under closely controlled test conditions. The extent of the scatter will depend on the consistency of surface condition, fabrication and the general quality of the springs which are tested. A leaf spring used in suspension will undergo a large number of cycles of small amplitude near the design load position without failure. Under greater amplitude the number of cycles without failure will be reduced, since the maximum stress as well as the stress range is increased, and both are determining factors in the fatigue life of a spring. Fatigue failures are typically characterized as either low-cycle $(<1,000$ cycles) or high-cycle ( $>1,000$ cycles).Most of the metals have a characteristic response to cyclic stresses. These materials have a threshold stress limit below which fatigue cracks will not initiate. This threshold stress value is often referred to as the endurance limit. Endurance limit may be defined as the highest level of alternating stress that a material can withstand without failure for infinite. The symbol for endurance limit is $S_{e}^{\prime}$. The endurance limit can be related to the tensile strength through the following relation

$$
\begin{aligned}
& S_{e}^{\prime}=0.5 \times S_{u t} \\
& S_{e}=\mathrm{k}_{\mathrm{a}} \times \mathrm{k}_{\mathrm{b}} \times k_{c} \times S^{\prime}{ }_{e}
\end{aligned}
$$

where $\mathrm{k}_{\mathrm{a}}$ is the surface factor, $\mathrm{kb}_{\mathrm{b}}$ is the size factor (gradient factor), and $\mathrm{k}_{\mathrm{c}}$ is the load factor. Fatigue life estimation using constant amplitude loading is a common practice to predict the fatigue life of leaf springs. To get more accurate fatigue life prediction, the actual case condition also needs to be considered. A fluctuating stress is a combination of static plus completely reversed stress. The components of the stresses are $S_{\min }$ is minimum stress, $S_{\max }$ is the maximum stress, $S_{a}$ is the stress amplitude or the alternating stress, $S_{\mathrm{m}}$ is the mean stress, $\Delta \mathrm{S}$ is the stress range, and $\mathrm{S}_{\mathrm{s}}$ is the steady or static stress. The steady or static stress is not the same as the mean stress. It can have any value between $\mathrm{S}_{\min }$ and $\mathrm{S}_{\max }$. This steady stress exists because of a fixed load and is usually independent of the varying 
portion of the load. The following relations between the stress components are useful and used to describe the fluctuating stress as in Fig. 2.

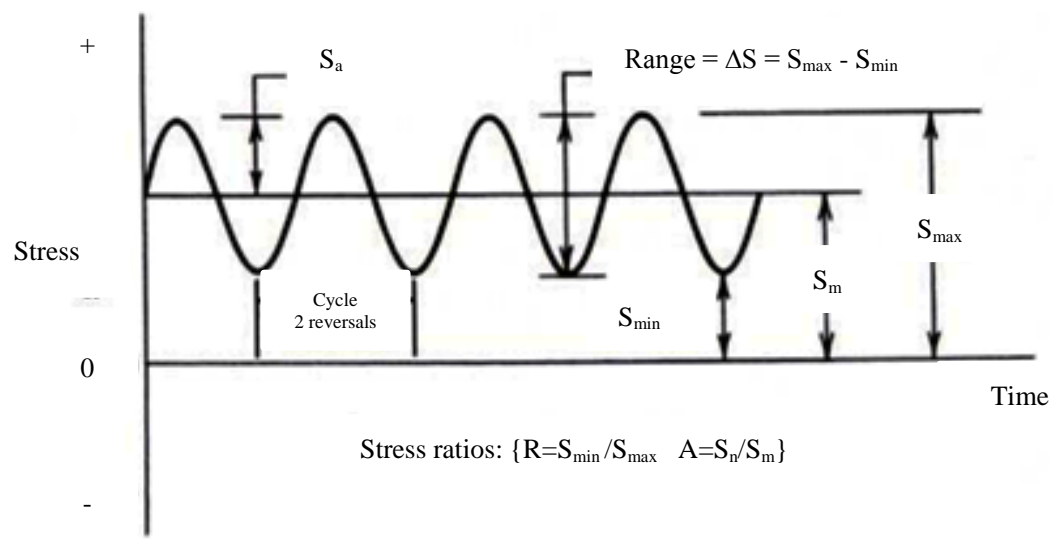

Fig. 2. Alternating fluctuating stress curve

In predicting the life of a component, a more useful presentation of fatigue life test data is the modified Goodman line diagram with relation of $\left(S_{\mathrm{a}} / S_{\mathrm{e}}+S_{\mathrm{m}} / S_{\mathrm{ut}}=1\right)$. These diagrams, while still limited by specimen geometry, surface condition, and material characteristics, afford the user to predict life at any stress ratio. The most common format used in the spring industry has the minimum operating stress along the $\mathrm{x}$-axis while the maximum operating stress is along the $y$-axis as in Fig. 3. Sufficient test data is generated to know the maximum and minimum stresses at various points that provide the same known life. Each of these points is plotted on the diagram. A line is then drawn through these points. Any combination of maximum and minimum stress that fall on the plotted line will be expected to have the known life. Points below the line will have a longer life; points above the line represent shorter life.

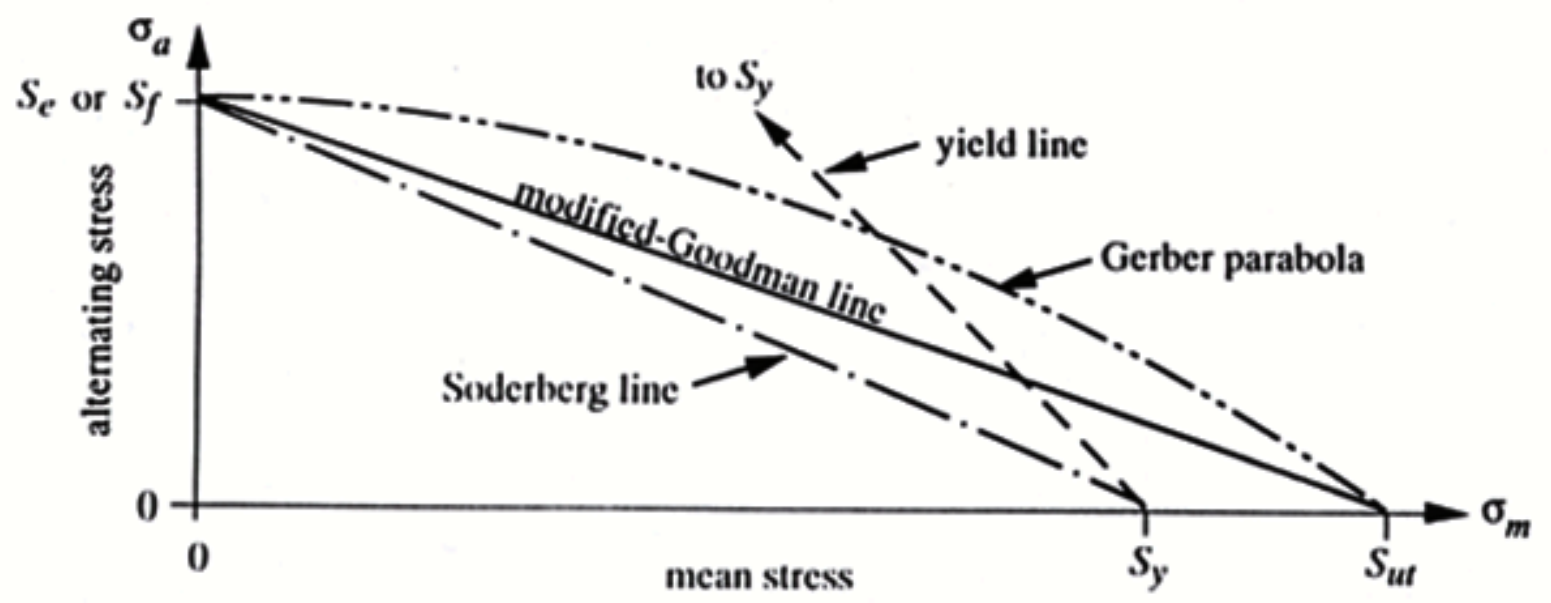

Fig. 3. Different fatigue design criteria

The above discussion touched on the relationship between applied stress and expected life. For the designer, it is critical that this relationship can be characterized so that fatigue life can be predicted. One of the early methods for characterizing this relationship is the S-N curve. ' $\mathrm{S}$ ' stands for the cyclic stress range while ' $\mathrm{N}$ ' represents the number of cycles to failure. To develop the curve, a series of samples is tested to failure at various stress ranges. The resulting lives are plotted versus the corresponding stress range. The S-N curve is the locus of these data points. In more thorough testing, multiple samples are tested at each stress range. Common practice is to plot the $\mathrm{S}-\mathrm{N}$ curve through the mean value at each stress range. Using an S-N curve to predict real-world life when conditions do not match the test conditions under which the curve was developed is dubious at best. This severely limits the use of S-N curves in product design. On the other hand, the ease of construction makes the S-N curve a simple and valuable tool in making relative comparisons between materials or process 
variations.

\section{Fatigue life analysis}

\subsection{Experimental fatigue life}

The experimental testing of EN45A parabolic leaf spring has been done in industrial laboratory. The chemical composition of EN45A spring steel used is $0.61 \mathrm{C}, 1.8 \mathrm{Si}, 0.79 \mathrm{Mn}, 0.02 \mathrm{~S}, 0.024 \mathrm{P}$, by percent weight. The mechanical properties are yield strength of $1147 \mathrm{MPa}$, ultimate tensile strength of $1256 \mathrm{MPa}$ and fatigue limit of $582 \mathrm{MPa}$. Full-scale testing of leaf spring was done for assessing the fatigue performance of parabolic leaf spring experimentally. Minimum alternating stress of $420 \mathrm{MPa}$ corresponds to the weight of vehicle only and maximum alternating stress of $900 \mathrm{MPa}$ corresponds to the load when leaf is near flat conditions. Full scale testing of leaf spring was carried out in an electrohydraulic fatigue component testing system (See Fig. 4). The leaf spring was placed in a fixture simulating the conditions of vehicle. The system consists of a hydraulic power pack to give hydraulic pressure and flow sent to a hydraulic actuator with a displacement specified by the alternating load. During this laboratory testing a total of 86823 number of stress cycles has been completed before the first deformation in the leaf spring assembly observed.

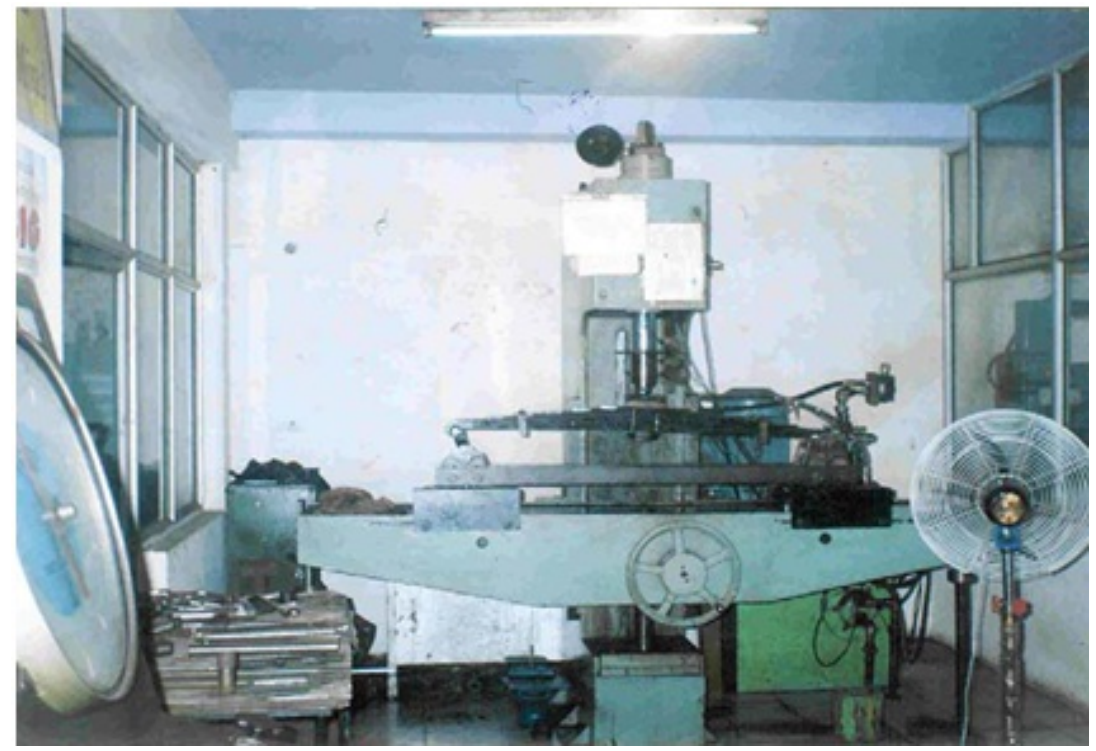

Fig. 4. Experimental testing on Full scale testing machine

\subsection{Fatigue life prediction by SAE spring design manual}

Fatigue life of leaf spring is expressed by the number of load cycles it will withstand without failure. A leaf spring used in a suspension system will undergo a large number of cycles of small amplitude near the design load without failure. Under the greater amplitude the number of cycles without failure will reduced, since the maximum stresses as well as the stress range are increased and both are determining factors in fatigue life of the spring. This criteria is frequently used for determination of fatigue life of the spring, initial stress(horizontal scale) and maximum stress (vertical scale) are intersected to estimate the number of cycles the spring will withstand for given loading condition as shown in the Fig. 5.

As per requirement of concerned industrial manufacturer the maximum and minimum load should be decided as per the criteria

$$
P_{\max / \min }=1.5 \pm 0.5 \mathrm{~g} \text {, }
$$


where ' $\mathrm{g}$ ' is design load and for stresses the criteria is as follows,

$$
\sigma_{\max / \min }=\frac{P_{\max / \min } \times L \times t}{8 \times \sum I_{\text {total }}} \text {. }
$$

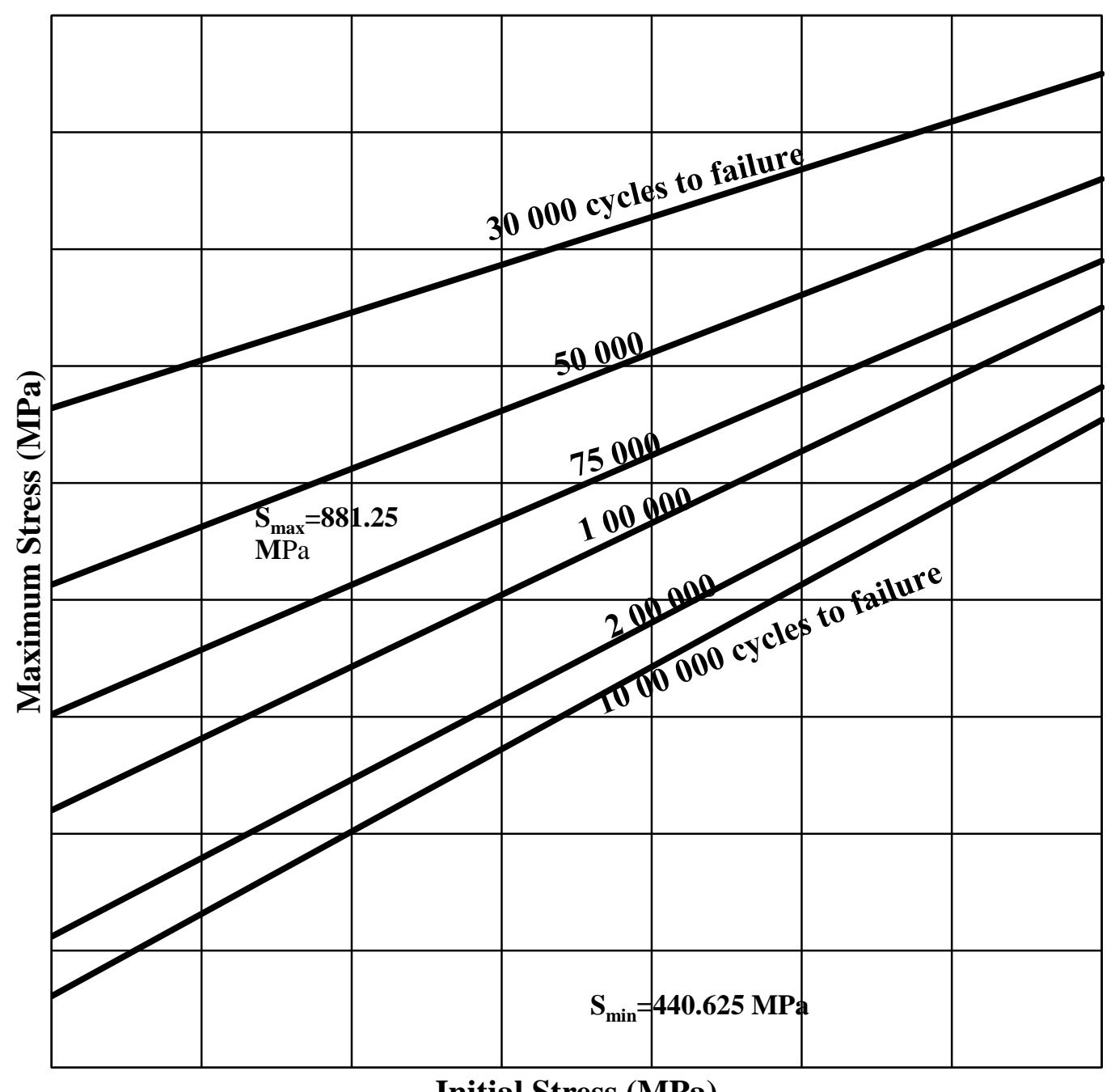

Initial Stress (MPa)

Fig. 5. SAE plot of fatigue life

The maximum stress (881.25MPa) and minimum stress (440.625MPa) intersects at a point to give an approximate estimated fatigue life of about 90000 stress cycles.

\section{CAE fatigue life prediction by ANSYS}

Fatigue life prediction is based on knowledge of both the number of cycles the part will experience at any given stress level during that life cycle and other influential environmental factors. In this present work prediction of the fatigue life by CAE tools has been done in which experimental and analytical fatigue life results are considered to compare with the results obtained in the CAE analysis for the purpose of validation. Fig. 6 and Table 1 show the boundary condition and loading environment of the model under consideration. 


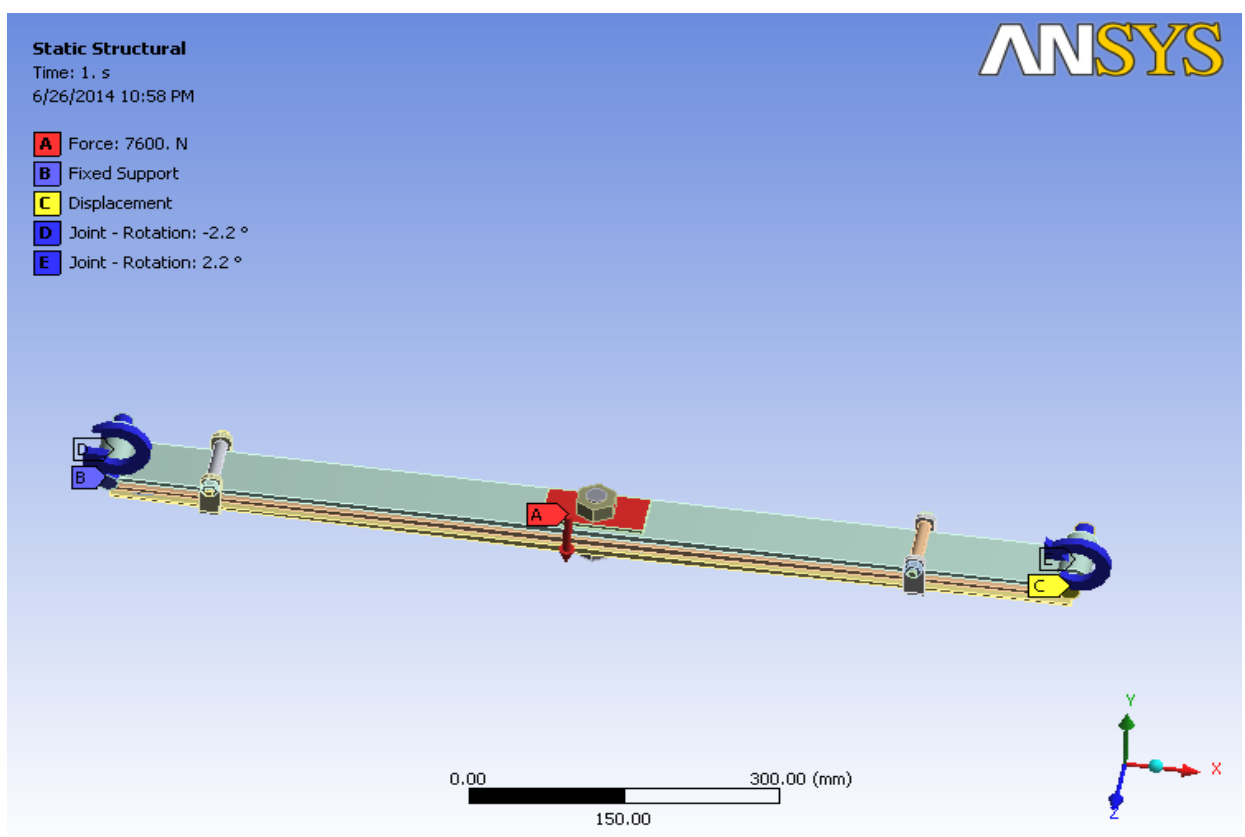

Fig. 6. Boundary conditions of leaf spring

Table 1. Model Table used for fatigue analysis of leaf

\begin{tabular}{lc}
\hline Object Name & Fatigue Tool \\
State & Solved \\
\hline Materials & 1. \\
\hline Fatigue Strength Factor (Kf) & \\
\hline Loading & Ratio \\
Type & 0.6 \\
Loading Ratio & 1. \\
Scale Factor & \\
\hline Options & Stress Life \\
Analysis Type & Goodman \\
Mean Stress Theory & Equivalent (Von Mises) \\
\hline Stress Component & \\
\hline
\end{tabular}

The mechanical properties in respect to the EN45A spring steel are detailed as in Table 2 below;

Table 2. Material data of leaf spring used in the FE analyses

\begin{tabular}{lc}
\hline Young's Modulus & $2 . \mathrm{e}+005 \mathrm{MPa}$ \\
Poisson's Ratio & 0.27 \\
Density & $7.85 \mathrm{e}-006 \mathrm{~kg} / \mathrm{mm}^{3}$ \\
Tensile Yield Strength & $1147 . \mathrm{MPa}$ \\
Tensile Ultimate Strength & $1256 . \mathrm{MPa}$ \\
Minimum Stress & $420 \mathrm{MPa}$ \\
Maximum Stress & $900 \mathrm{MPa}$ \\
Mean Value & $660 . \mathrm{MPa}$ \\
Stress Amplitude & $240 \mathrm{MPa}$ \\
Endurance Limit & $582 \mathrm{MPa}$ \\
\hline
\end{tabular}


Fatigue failure of any mechanical component always starts with a crack-growth. The crack can initiate from the surface or at a depth below the surface depending on the material processing conditions or from the stress concentrators such as pre notches, cracks, holes and etc. (Torabi \& Aliha, 2013). Fatigue test using constant amplitude loading is a commonly practiced to predict the fatigue life properties of materials. As this work belongs to fatigue life of the parabolic leaf spring thus the target results which can be considered for its prediction are life and alternating stress developed in the assemblies which are shown in the Fig. 7 and Fig. 8, respectively. Vehicle which has been installed with this leaf spring was selected to perform the constant amplitude loading data collection.

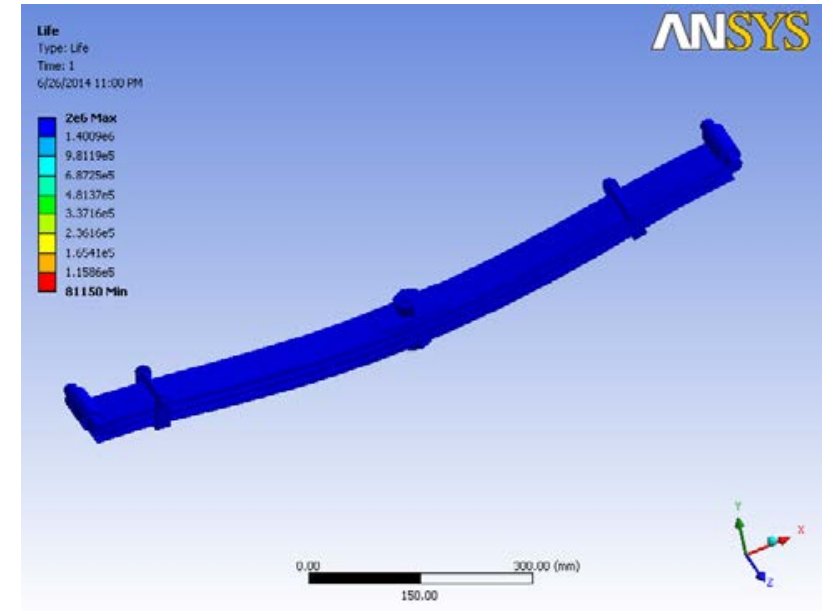

Fig. 7. Life in CAE analysis

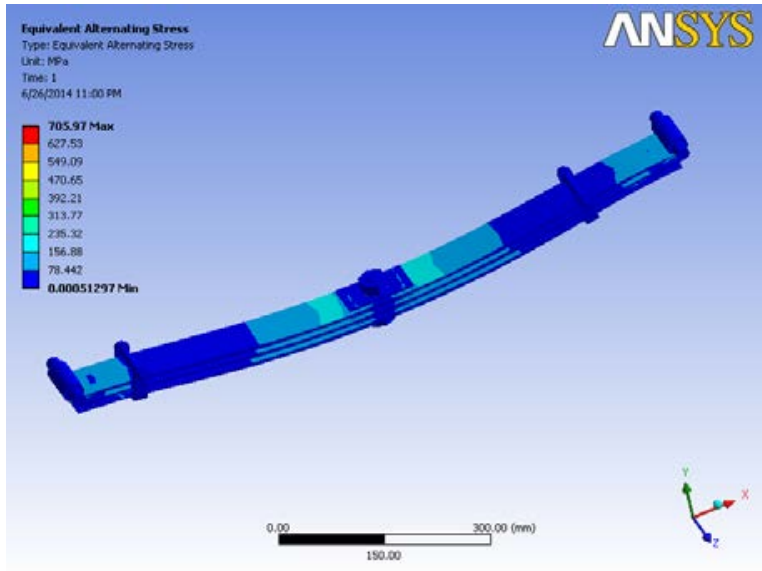

Fig. 8. Equivalent alternating stress in CAE analysis

Table 3 shows the target results obtained from the CAE analysis of fatigue life which are to be considered for fatigue life prediction. Here a total number of 81150 cycles have been noted before failure of the parabolic leaf spring with an equivalent alternating stress level of 705.97 MPa.

Table 3. Result of life and equivalent alternating stress

\begin{tabular}{|c|c|c|c|}
\hline Object Name & Life & Equivalent Alternating Stress & Damage \\
\hline State & \multicolumn{3}{|c|}{ Solved } \\
\hline \multicolumn{4}{|l|}{ Scope } \\
\hline Geometry & \multicolumn{3}{|c|}{ All Bodies } \\
\hline \multicolumn{4}{|l|}{ Definition } \\
\hline Type & Life & Equivalent Alternating Stress & Damage \\
\hline Design Life & & & 1.e+009 cycles \\
\hline \multicolumn{4}{|l|}{ Results } \\
\hline Minimum & 81150 cycles & 5.1297e-004 MPa & \\
\hline Minimum Occurs On & Part2 & Part23.1 & \\
\hline Maximum & & $705.97 \mathrm{MPa}$ & 12323 \\
\hline Maximum Occurs On & & Part2 & \\
\hline
\end{tabular}

The S-N plot for the model under consideration plotted by CAE approach is shown in Fig. 9. 


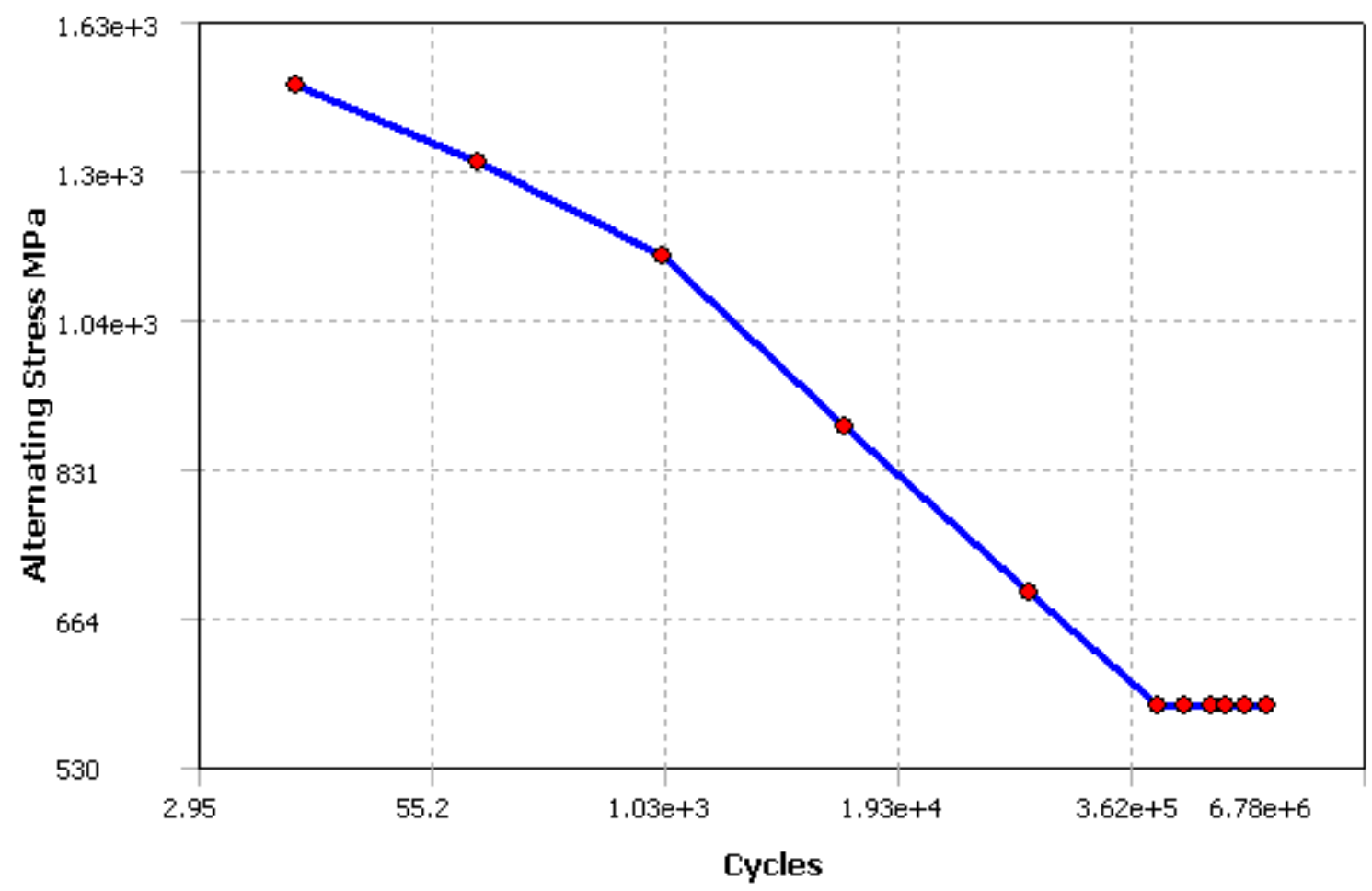

Fig. 9. S-N curve of CAE analysis

\section{Result Comparison}

All fatigue life results obtained by different methods are now be compared for the purpose of validation. This work involves fatigue life analysis of a parabolic leaf spring under fluctuating load. Before conclusion it should be explained that the experimental testing of leaf spring has been done on actual assembly which has been shot peened. So there may be some variation in the results of other methodologies.

Table 4. Result Comparison of fatigue lives

\begin{tabular}{lccc} 
& Experimental & SAE Manual & CAE Approach \\
$\begin{array}{l}\text { Fatigue Life of Leaf } \\
\text { spring before failure }\end{array}$ & 86823 cycles & 90000 cycles & 81150 cycles \\
\hline
\end{tabular}

\section{Conclusion}

From the results obtained from Experimental, SAE \& CAE methodologies it has been concluded that:

1. The fatigue life obtained through experimental testing \& SAE analysis are $86823 \& 90000$ respectively, which shows a $3.66 \%$ variation which is acceptable.

2. The fatigue life obtained through experimental testing \& CAE analysis are $86823 \& 81150$ respectively, which shows a $6.54 \%$ variation which is acceptable.

3. The equivalent alternating stress obtained in CAE analysis is $705.97 \mathrm{MPa}$ which is also under safe region. 


\section{References}

Abdullah, S., Refngah, F. N., Jalar, A., Chua, I. B., Ariffin, A. K., \& Zaharim, A. (2008, November). FEA-based durability assessment: A case study using a parabolic leaf spring. In Proceedings of the 7th WSEAS international conference on System science and simulation in engineering (pp. 67-72). World Scientific and Engineering Academy and Society (WSEAS).

Aggarwal, M. L., \& Chawla, P. S. (2007). Issues in fretting fatigue design of shot peened leaf springs. Indian Journal of Engineering and Materials Sciences, 14(6), 414.

Aggarwal, M. L., Agrawal, V. P., \& Khan, R. A. (2006). A stress approach model for predictions of fatigue life by shot peening of EN45A spring steel.International journal of fatigue, 28(12), 18451853.

Aggarwal, M. L., Khan, R. A., \& Agrawal, V. P. (2006). Effect of surface roughness on the fretting fatigue behaviour of EN45A spring steel. Proceedings of the Institution of Mechanical Engineers, Part B: Journal of Engineering Manufacture, 220(8), 1325-1331.

Aggarwal, M. L., Khan, R. A., \& Agrawal, V. P. (2005). Influence of shot peening intensity on fatigue design reliability of 65Si7 spring steel. Indian Journal of Engineering and Materials Sciences, 12(6), 515.

Aggarwal, M. L. (2012). Modeling of Shot Peening Parameters for Weight Reduction of EN45A Spring Steel Leaf Springs. AASRI Procedia, 3, 642-645.

Černý, I., \& Mayer, R. M. (2012). Fatigue of selected GRP composite components and joints with damage evaluation. Composite structures, 94(2), 664-670.

Refngah, F. A., Abdullah, S., Jalar, A., \& Chua, L. B. (2009). Fatigue life evaluation of two types of steel leaf springs. International Journal of Mechanical and Materials Engineering (IJMME), 4(2), 136-140.

Kanbolat, A., Soner, M., Erdogus, T., \& Karaagac, M. (2011).Parabolic leaf spring optimization and fatigue strength evaluation on the base of road load data, endurance rig tests and non linear finite element analysis (No. 2011-01-0438). SAE Technical Paper.

Karthik, J. P., Chaitanya, K. L., \&Sasanka, C. T. (2012).Fatigue life prediction of a parabolic spring under non-constant amplitude proportional loading using finite element method. International Journal of Advanced Science and Technology, 46, 143-156.

Krishan Kumar et al (2013). CAE simulation approach for static and dynamic analysis of leaf springs. in the proceedings of3rd International Conference on Production and Industrial Engineering, 143153

Kumar, K., \& Aggarwal, M. L. (2013). Computer aided FEA simulation of EN45A parabolic leaf spring. International Journal of Industrial Engineering Computations, 4(2), 297-304.

Kumar, M. S., \&Vijayarangan, S. (2007). Analytical and experimental studies on fatigue life prediction of steel and composite multi-leaf spring for light passenger vehicles using life data analysis. Materials science, 13(2), 141-146.

Refngah, F. A., Abdullah, S., Jalar, A., \& Chua, L. B. (2009a). Life assessment of a parabolic spring under cyclic strain loading.European Journal of Science Research, 28, 351-353.

Scuracchio, B. G., de Lima, N. B., \& Schon, C. G. (2013).Role of residual stresses induced by double peening on fatigue durability of automotive leaf springs. Materials \& Design, 47, 672-676.

Sustarsic, B., Borkovic, P., Echlseder, W., Gerstmayr, G., Javidi, A., \&Sencic, B. (2011).Fatigue strength and microstructural features of spring steel. Integritetivekkonstrukcija, 11(1), 27-34.

SAE. (1980). Manual on Design and application of leaf spring, SAE HS-788.

Torabi, A., \& Aliha, M. (2013). Determination of permissible defect size for solid axles loaded under fully-reversed rotating bending. Engineering Solid Mechanics, 1(1), 27-36. 